\title{
Studies in Adsorption: Measurement of External Specific Surface Area of Metal Ferrocyanides by Methylene Blue Dye Adsorption
}

\author{
B.B. Tewari'and M.V. Boodhoo \\ Department of Chemistry, Faculty of Natural Sciences, University of Guyana, P.O. Box: 101110, \\ Georgetown, Guyana (S.America)
}

\begin{abstract}
Solution adsorption of cationic methylene blue dye at room temperature is suitable for specific surface area measurements on a wide variety of solids. The experimental procedure is simple and the results with a variety of organic and inorganic solids are generally in good agreement with those of other adsorption methods. Adsorption of methylene blue dye in the concentration range $\left(10^{-5}-10^{-6} \mathrm{M}\right)$ on antimony, cadmium and zirconium ferrocyanides was studied in the $\mathrm{pH}$ range $(2.0-10.0)$ at room temperature $\left(30 \pm 1^{\circ} \mathrm{C}\right)$. The nature of the adsorption has been interpreted from the shape of adsorption isotherms. Methylene blue adsorption on these metal ferrocyanides followed Langmuir adsorption isotherm. The methylene blue appears to be adsorbed flatwise from water with an effective molecular area of $130 \AA^{2}$. Results of the present study indicate that cadmium ferrocyanide is highly porous with specific surface area of $101.67 \pm 0.02 \mathrm{~m}^{2} \mathrm{~g}^{-1}$.
\end{abstract}

Keywords: Methylene blue dye; Adsorption; Metal ferrocyanides; Specific surface area.

\section{INTRODUCTION}

The measurement of specific surface area of finally divided solids becomes increasingly important in laboratory and technical processes. One of the most widely employed methods for such measurements is vapour-phase adsorption of nitrogen, or other gases or vapours $/ 1$. Solute adsorption however offers several advantages over these adsorption. methods (or e.g. p-nitrophenol solution adsorption etc.) for the determination of specific surface area $/ 2 \%$.

Due to the ease of formation of cyanide under prebiotic conditions $/ 3 /$, it is thought that cyanide might have formed stable complexes with the abundant transition metal ions present in the primeval seas. It is further assumed that, during the course of chemical evolution, cyanide could also have formed some insoluble metal ferrocyanides of general formula $\mathrm{M}_{2}\left[\mathrm{Fe}(\mathrm{CN})_{6}\right] \cdot \mathrm{xH}_{2} \mathrm{O}$, where $\mathrm{M}=\mathrm{Cu}^{2+}, \mathrm{Zn}^{2+}, \mathrm{Cd}^{2+}$ etc. These insoluble metal ferrocyanides have acted as well known adsorbent $/ 4-8 /$ and ion-exchangers $/ 9,10 /$. Due to 
various characteristic properties of metal hexacyanoferrate(II) complexes, it seems useful to determine the specific surface area of these compounds, since for porous solids the area of the surface accessible to a solute is greater than the geometric area. Dye adsorption, preferentially the uptake of methylene blue, has been often used as a substitute for BET measurement for determining the total surface of such compounds $/ 11,12 /$.

A search of the literature indicated some reports /13-17/ on determination of specific surface area of solids by methylene blue dye adsorption, but no report was available on specific surface area of metal ferrocyanides. In view of this, an attempt has been made to determine the specific surface area of metal ferrocyanides. In addition, the present paper describes determination of specific surface area (SSA) of antimony ferrocyanide $(\mathrm{SbFc})$, cadmium ferrocyanide $(\mathrm{CdFc})$ and zirconium ferrocyanide $(\mathrm{ZrFc})$ by methylene blue $(\mathrm{MB})$ dye adsorption.

\section{EXPERIMENTAL}

\section{Materials}

All chemicals used were of AnalaR grade. Potassium ferrocyanide, antimony chloride, cadmium chloride and zirconyl chloride were obtained from BDH, Poole, UK. Methylene blue dye was obtained from E.Merck, Darmstadt Germany. All solutions were prepared in double-distilled water.

\section{Synthesis and characterization of metal ferrocyanides.}

Antimony, cadmium and zirconium ferrocyanides were synthesized similarly to the methods reported in chemical literature $/ 18,19 /$. The metal hexacyanoferrate(II) complexes were characterized on the basis of elemental and spectral studies. The percentage composition of metals were determined by IL-751 atomic absorption spectrophotometer. Carbon, hydrogen and nitrogen analysis were carried out by CEST-118, CHN analyzer. The values are given in Table 1.

Table 1

Elemental analysis of antimony,cadmium and zirconium ferrocyanides

\begin{tabular}{|c|c|c|c|c|c|}
\hline \multirow{2}{*}{ Metal ferrocyanides } & \multicolumn{5}{|c|}{ Percentage found } \\
\cline { 2 - 6 } & Metal & Iron & Carbon & Hydrogen & Nitrogen \\
\hline $\mathrm{SbFc}$ & 47.50 & 12.50 & 15.25 & 0.89 & 17.79 \\
\hline $\mathrm{CdFc}$ & 41.59 & 11.50 & 15.13 & 1.69 & 17.37 \\
\hline $\mathrm{ZrFc}$ & 34.66 & 10.30 & 12.97 & 2.90 & 15.41 \\
\hline
\end{tabular}

${ }^{a} \mathrm{SbFc}=$ antimony ferrocyanide; $\mathrm{CdFc}=$ cadmium ferrocyanide;

$\mathrm{ZrFc}=$ zirconium ferrocyanide.

Antimony,cadmium and zirconium ferrocyanides were found to have light blue, light green and gray colours, respectively. All three metal ferrocyanides are amorphous solids and give no X-ray lines. Metal 
ferrocyanides were found to be stable in acids $\left(\mathrm{HCl}, \mathrm{HNO}_{3}, \mathrm{H}_{2} \mathrm{SO}_{4}\right)$ bases $\left(\mathrm{NaOH}, \mathrm{KOH}, \mathrm{NH}_{4} \mathrm{OH}\right)$ and various salt $\left(\mathrm{NaCl}, \mathrm{KCl}, \mathrm{LiCl}, \mathrm{NH}_{4} \mathrm{Cl}, \mathrm{RbCl}, \mathrm{CsCl}, \mathrm{BaCl}_{2}\right.$ and $\mathrm{CaCl}_{2}$ ) solutions in the concentration range 1.0 $-2.0 \mathrm{M}$.

Infrared spectra of the compounds, $\mathrm{M}_{2}\left[\mathrm{Fe}(\mathrm{CN})_{6}\right] \cdot \mathrm{x}_{2} \mathrm{O}$ [where $\mathrm{M}=\mathrm{Sb}, \mathrm{x}=2 ; \mathrm{M}=\mathrm{Cd} \mathrm{x}=4$ and $\mathrm{M}=\mathrm{Zr}$, $x=8$ ], were recorded in $\mathrm{KBr}$ disc on Beckmann IR -20 spectrophotometer. All three metal ferrocyanides show a broad peak at $3600 \mathrm{~cm}^{-1}$, characteristic of water molecule and $\mathrm{OH}$ group. Another peak at around $1600 \mathrm{~cm}^{-1}$ is due to $\mathrm{HOH}$ bending. Two sharp bands at $2000 \mathrm{~cm}^{-1}$ and $600 \mathrm{~cm}^{-1}$ are characteristic of cyanide and Fe-C stretching, respectively. Another sharp band at around $490 \mathrm{~cm}^{-1}$ probably shows the presence of metal-nitrogen bond due to polymerization /20/.The infrared spectral data are given in Table 2 .

Table 2

Infrared spectral data of antimony,cadmium and zirconium ferrocyanides

\begin{tabular}{|c|c|c|c|c|c|}
\hline \multirow[b]{2}{*}{$\begin{array}{c}\text { Metal } \\
\text { ferrocyanides }\end{array}$} & \multicolumn{5}{|c|}{ Absorption frequences $\left(\mathrm{cm}^{-1}\right)$} \\
\hline & $\begin{array}{c}\mathrm{H}_{2} \mathrm{O} \text { molecules } / \mathrm{OH} \\
\text { group }\end{array}$ & HOH bending & $\mathrm{C}=\mathrm{N}$ stretching & $\mathrm{Fe}-\mathrm{C}$ & Metal - $\mathrm{N}^{\mathrm{b}}$ \\
\hline $\mathrm{SbFc}$ & 3600 & 1600 & 2000 & 580 & 490 \\
\hline $\mathrm{CdFc}$ & 3600 & 1620 & 2000 & 600 & 490 \\
\hline $\mathrm{ZrFc}$ & 3600 & 1600 & 2000 & 600 & 500 \\
\hline
\end{tabular}

${ }^{\mathrm{h}}$ Metal $-\mathrm{N}$ band shows degree of polymerization.

\section{Adsorption studies}

The adsorption of methylene blue dye on antimony, cadmium and zirconium ferrocyanides as a function of $\mathrm{MB}$ concentration $\left(10^{-5}-10^{-6} \mathrm{M}\right)$ in $\mathrm{pH}$ range $(1.0-10.0)$ was studied at room temperature $\left(31^{\circ} \mathrm{C}\right)$. A series of $15 \mathrm{ml}$ test tubes were employed. Each tube was filled with $10 \mathrm{ml}$ of $\mathrm{MB}$ solution of different concentration and adjusted to desired $\mathrm{pH}$ by dilute $\mathrm{HCl} / \mathrm{NaOH}$ solution. $25 \mathrm{mg}$ of each metal ferrocyanide was added in each test tube and agitated for $24 \mathrm{~h}$. Equilibrium was attained in $6 \mathrm{~h}$. The suitable equilibrium time and concentration range, were however, decided after a good deal of preliminary investigations. The concentration of methylene blue was measured spectrophotometrically at $\lambda_{\max } 661 \mathrm{~nm}$.

\section{RESULTS AND DISCUSSION}

The variation of adsorption of methylene blue dye on antimony, cadmium and zirconium ferrocyanides with varying hydrogen ion concentrations is given in Figure 1. Cadmium and antimony ferrocyanides exhibited maximum adsorption at $\mathrm{pH} 2.0$, while zirconium ferrocyanide has a maximum adsorption at $\mathrm{pH}$ 4.0. $\mathrm{SbFc}, \mathrm{CdFc}$ and $\mathrm{ZrFc}$ showed minimum adsorption at $\mathrm{pH} 4.0,10.0$ and 2.0, respectively. A neutral $\mathrm{pH}$ was chosen to run the adsorption isotherms of the methylene blue dye in a wide range of concentration because most biological redox reactions take place in neutral medium. 


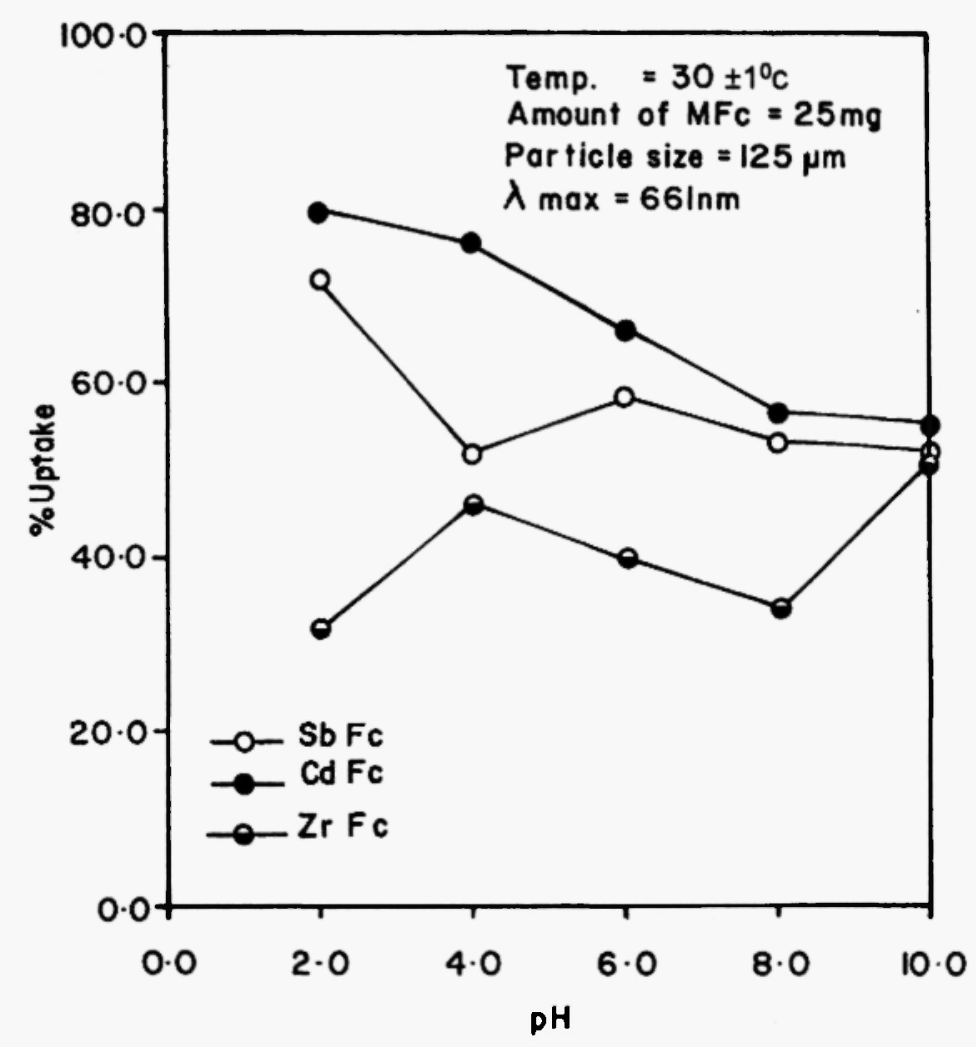

Fig. 1: Effect of $\mathrm{pH}$ on adsorption of methylene blue dye on metal ferrocyanides.

Adsorption isotherms for methylene blue dye on $\mathrm{SbFc}, \mathrm{CdFc}$ and $\mathrm{ZrFc}$ are shown in Figure 2. The isotherms are positive and concave to the concentration axis. At low concentration adsorption is rapid, then slows down at higher concentration until adsorption becomes constant and the graph levels off. This leveling off or 'plateau' indicates the saturation point (point at which there is maximum uptake of dye). The order of maximum uptake of methylene blue dye on metal ferrocyanides is as follows:

\section{$\mathrm{CdFc}>\mathrm{SbFc}>\mathrm{ZrFc}$}

Plots of 1/Ceq against 1/qeq for adsorption of MB dye on SbFc, CdFc and $\mathrm{ZrFc}$ are shown in Figure 3. The straight line of each plot shows the Langmuir type of adsorption in general. The data are analyzed in terms of the well known linear Langmuir equation

$$
1 / \mathrm{q}_{\mathrm{eq}}=1 / \mathrm{Q}^{\circ}+1 / \mathrm{C}_{\mathrm{eq}} \cdot 1 / \mathrm{bQ}^{\circ}
$$

where $\mathrm{q}_{\mathrm{cq}}$ is $\mathrm{mg}$ of solute adsorbed per gram of adsorbent. $\mathrm{Q}^{\circ}$ is adsorption maximum, i.e. $\mathrm{mg}$ of methylene blue required per gram of metal ferrocyanide to form a complete monolayer on the surface, $\mathrm{C}_{\mathrm{rq}}$ is equilibrium concentration of methylene blue, $b$ is related to equilibrium constants or bonding energy $\left(b=\alpha e^{-\Lambda H / R T}\right.$, the parameter $b$ reflects the steepness of the approach to the saturation; more precisely, the $b$ value is the reciprocal of concentration at which half-saturation of adsorbent is attained). 


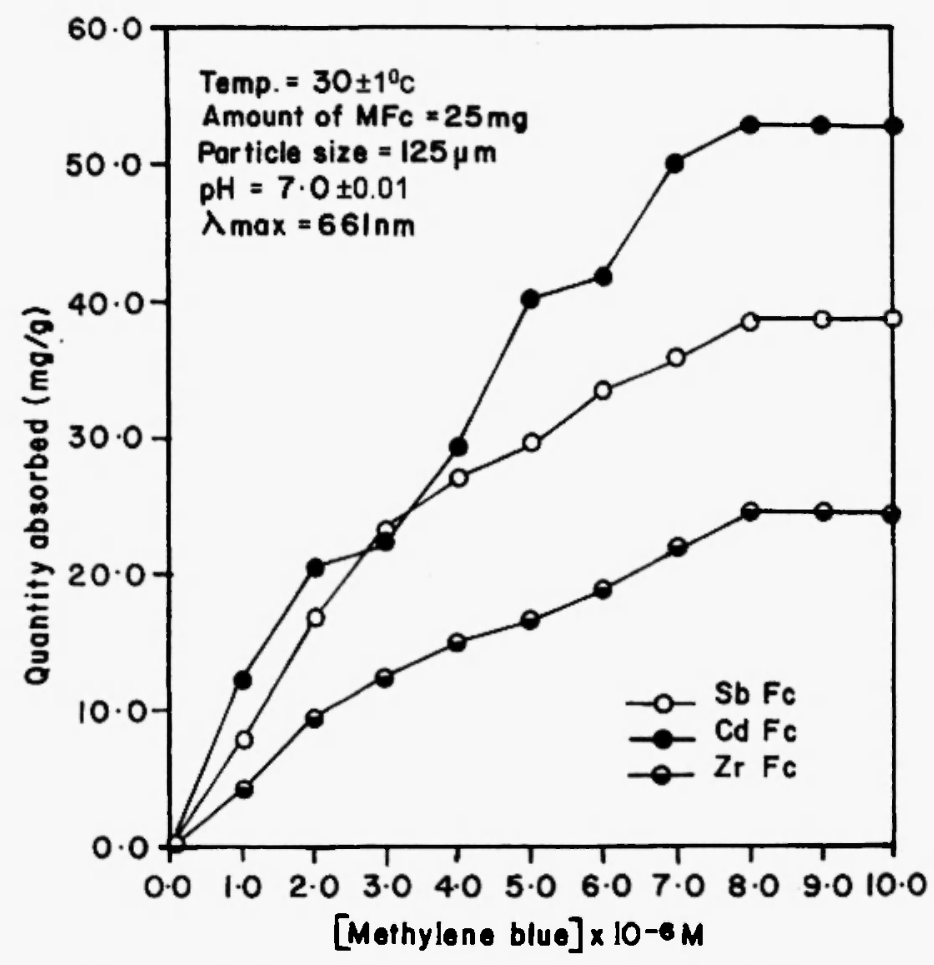

Fig. 2: Adsorption isotherm of methylene blue dye on metal ferrocyanides.

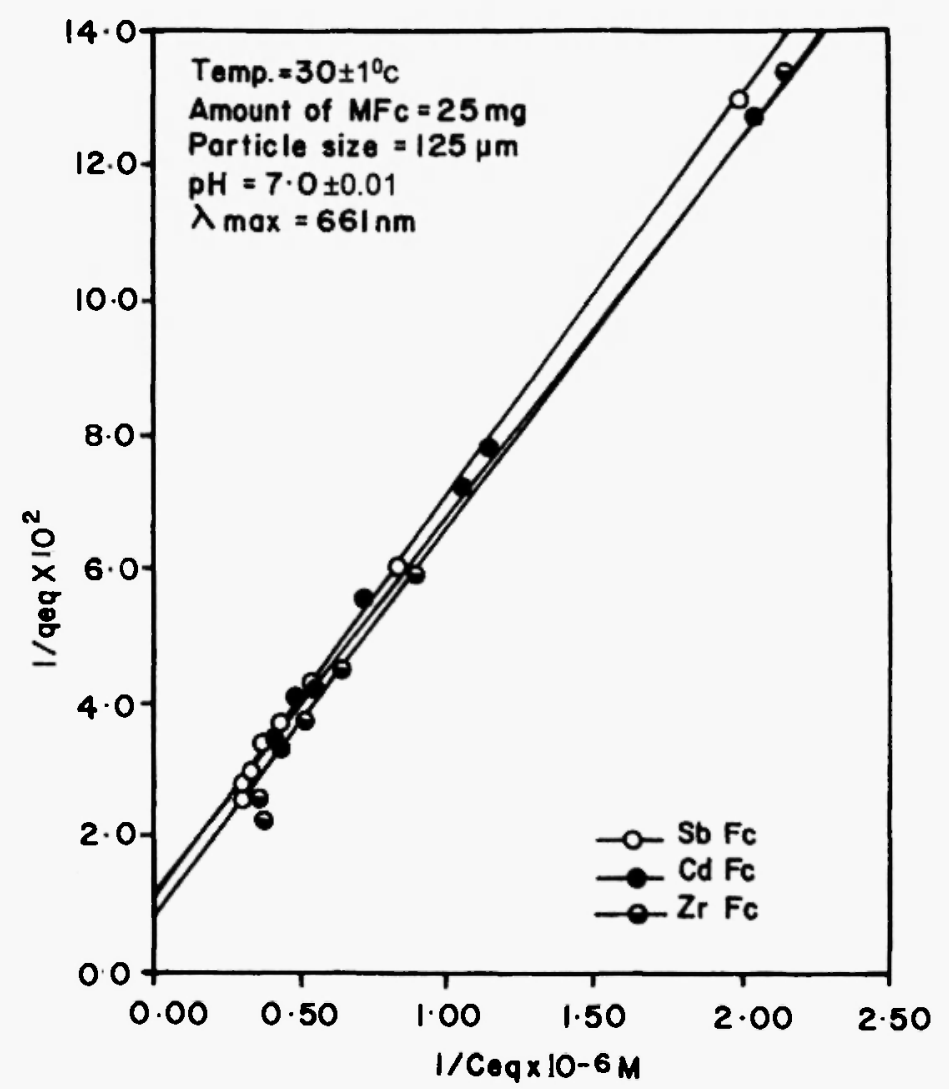

Fig. 3: Langmuir plots of methylene blue dye on metal ferrocyanides. 
The Langmuir constants $b$ and $\mathrm{Q}^{\circ}$ were obtained from the slope and intercept of Figure 3. The calculated values of Langmuir constants are given in Table 3. At higher concentration of methylene blue (greater than $10^{-3} \mathrm{M}$ ), Langmuir plots deviate from linear behaviour, probably due to formation of multilayers $/ 21$.

Table 3

Langmuir constants for adsorption of methylene blue dye on metal ferrocyanides

\begin{tabular}{|c|c|c|cc|}
\hline \multirow{2}{*}{ Metal ferrocyanides } & Particle size & Specific surface area & \multicolumn{2}{|c|}{ Langmuir constants } \\
\cline { 3 - 5 } & $(\mu \mathrm{m})$ & $\begin{array}{c}\mathrm{b} \times 10^{-5} \\
\left(\mathrm{~m}^{2} \mathrm{~g}^{-1}\right)\end{array}$ & $\mathrm{Q}^{\prime \prime}(\mathrm{mg} / \mathrm{g})$ \\
\hline $\mathrm{SbFc}$ & 125 & $74.30 \pm 0.09$ & $1.82 \pm 0.07$ & $100.00 \pm 0.05$ \\
\hline $\mathrm{CdFc}$ & 125 & $101.67 \pm 0.02$ & $1.01 \pm 0.10$ & $271.43 \pm 0.08$ \\
\hline $\mathrm{ZrFc}$ & 125 & $47.03 \pm 0.05$ & $2.12 \pm 0.11$ & $71.43 \pm 0.03$ \\
\hline
\end{tabular}

(Temperature $=30 \pm 1^{\circ} \mathrm{C} ; \mathrm{pH}=7.0 \pm 0.01 ;$ methylene blue dye $\lambda_{\text {max }}=661 \mathrm{~nm}$ )

The specific surface area of metal ferrocyanides was calculated by using the equation $/ 22,23 /$.

$$
\text { Specific Surface Area }(\mathrm{SSA})=6.02 \times 10^{-2} \mathrm{M}_{\mathrm{f}} \mathrm{A}_{\mathrm{m}}\left(\mathrm{m}^{2} \mathrm{~g}^{-1}\right)
$$

where $\mathrm{M}_{\mathrm{f}}$ is the amount of methylene blue $(\mathrm{mM})$ adsorbed per $100 \mathrm{~g}$ of metal ferrocyanide, when the surface is covered with a monolayer, $A_{m}$ is the area per molecule in $\AA^{2}$ on the surface. Under the condition of optimum flocculation, the area per adsorbed molecule of $\mathrm{MB}$ is taken as $130 \AA^{2}$, which corresponds to the molecule lying flat on the adsorbent surface. The calculated specific surface area values of metal ferrocyanides are given in Table 3.

It is clear from Table 3 that $\mathrm{CdFc}$ and $\mathrm{ZrFc}$ have maximum and minimum surface area, respectively. Hence $\mathrm{CdFc}$ is considered to be more porous in comparison to other metal ferrocyanides studied. The use of basic methylene blue dye for the determination of SSA is more useful, because it is highly pure and suitable for immediate use, as this dye is easily analyzed spectrophotometrically. Most of the solids acquire a negative charge in water and this easily attracts dye cations. Determination of SSA by MB dye adsorption is simple, rapid and reliable, therefore the present method has significant advantages over other methods reported in chemical literature for the determination of SSA of solids.

\section{REFERENCES}

1. S. J. Gregg and K.S.W. Sing, Adsorption Surface Area and Porosity, London, Academic Press, 1967.

2. A.J. Haley, J. Appl. Chem., Lond. 13, 392 (1963).

3. M.T. Beck, in Sigel H. (ed.), Metal lons in Biological Systems, $7^{\text {th }}$ Ed. Marcel Dekker, New York, 1978; p. 1 
4. B. B. Tewari and Kamaluddin, J. Colloid Interface Sci. 193. 167 (1997).

5. Kamaluddin, M. Nath, S. W. Deopujari and A. Sharma, Origins Life Evol. Biosphere, 20, 259 (1990).

6. Kamaluddin, M. Nath and A. Sharma, Origins Life Evol. Biosphere 24, 469 (1994).

7. B.B. Tewari, D. Mohan and Kamaluddin, Colloids and Surfaces 131, 89 (1998).

8. B.B. Tewari, Rev. Anal. Chem. 19, 491 (2000).

9. I.P. Saraswat, S.K. Srivastava and S. K. Sharma, J. Inorg. Nucl. Chem. 43, 1653 (1981).

10. J.S. Gill and S.N. Tandon, J. Inorg. Nucl. Chem. 34, 3885 (1972).

11. P.G. Smith and P. Coackley, Wat. Res. 17, 595 (1983).

12. R. Brina and A. D. Battisti, J. Chem. Edu. 64, 175 (1987).

13. F. Guzel and I. Uzum, Turk J. Chem. 26. 369 (2002).

14. O. Inel and F. Tumsek, Turk. J. Chem. 24, 9 (2000).

15. C. Kacwprasit, E. Hequet, N. Abidi and J. P. Gourlot, J. Cotton Sci. 2, 164 (1998).

16. A. A. Attia, B. S. Girgis and S. A. Khedr, J. Chem. Technol. Biotechnol. 78, 611 (2003).

17. B. Hennessy, S. Megelski, C. Marcolli, V. Shklover, C. Barlocher and G. Calzaferri, J. Phys. Chem. B, 103, 3340 (1999).

18. B.B. Tewari, D. Mohan, Kamaluddin and S. K. Srivastava, Indian J. Chem. Technol. 2, 113 (1995).

19. V. Kourim, J. Rais and B. Million, J. Inorg. Nucl. Chem. 26, 1111 (1964).

20. P. Pantnasamy and A. J. Leonard, J. Phys. Chem. 76, 1838 (1976).

21. M. A. Rahman and A. K. Ghosh, J. Colloid Interface Sci. 77, 50 (1980).

22. G. W. Brindley and T. D. Thompson, Clays Clay Miner. 18, 203 (1970).

23. G. H. Giles, A. P. D'Silva and A. S. Trivedi, J. Appl. Chem. 20, 37 (1970). 
